\title{
She, You and They - More Actors on the Creativity Research Stage!
}

\section{Eva Hoff}

Lund University, Sweden

E-mail: eva.hoff@psy.lu.se

\section{Ingegerd Carlsson}

Lund University, Sweden

E-mail: ingegerd.carlsson@psy.lu.se
ARTICLE INFO

\section{Keywords:}

Creativity research

Theoretical critique

Creativity measurement

Creativity definition

Group creativity

\section{Article history:}

Received 6 November 2014

Received in revised form 17 February 2015

Accepted 21 February 2015

ISSN: 2354-0036

DOI: 10.1515/ctra-2015-0005
A B S TRACT

The commentary confirms and builds on Glăveanu's critical scrutiny of the current stage of creativity research. The need for more actors, theories, methods and definitions will not be fulfilled until critical reflection concerning what has been done and synthesis between different research attempts are achieved. The authors first expand the creativity stage by discussing what will happen in creativity research attempts if we alternate with a "she, you and they" perspective? They then present a new definition of creativity. Creativity is seen as a collective, generative, novel way of experiencing reality ending with the idea of a shared product that is evaluated as creative in a relevant context. This definition is in line with the development of a new creativity tool or measurement, the Test for Distributed Creativity in Organizational Groups (DOG). The DOG can be used both for measuring the products of creative groups and investigating their processes.

Is the creativity field close to a crisis? We would like to first state that in itself a crisis is not something bad. Crisis means turning-point. We hope that Glăveanu's seminal attempt to create a dialogue will lead to new and valuable input - or effective surprise - to the creative stage (Glăveanu, 2014). He asserts that the field is productive in the accumulation of more and more studies, but at the same time has stagnated theoretically. "We need to build more systematically on what we have achieved" (p. 26).

Recently, one colleague came and complained that nobody wanted to pass on the efforts of the late creativity professor's work anymore, concerning research on creative micro-processes. The colleague had herself tried to find apprentices in the field, but now announced that she was giving up. Despite the fact that the professor had written about his ideas well into his 80-ies and people internationally had started similar work (Brown, 2008; Draguns, 2008), after his death the younger generation of researchers had not continued the work. His work on a process model of personality also included creative processes (Smith, 2001; Smith \& Carlsson, 1990). The professor had dealt with questions 
of how the processes of being and becoming a person thoroughly influence and can also be scientifically captured in the person's perception and understanding of the world including the individual's creative perception. A large share of the research effort was dedicated to the development and validation of various measures of the perceptual process, in order to experimentally study aspects of the personality based on a psychodynamic framework. Perhaps the strong focus on measurement was one reason why the model did not find its way into mainstream psychology. Experimental research efforts are often dependent on the measurement of creativity and measurement might also constitute a limitation to its implications, as indeed Glăveanu asserts in his article (2014). In this case, the testing of creative potential could only be done under exact laboratory conditions, and over the years a lot of effort was spent on computerizing the measurement. A possible continuation of the professor's model of the micro-processes of creativity would also have been to find ways of investigating it outside the laboratory in real life contexts or as Hutchins puts it, "in the wild” (Hutchins, 2012).

One of the critical points that Glăveanu brings up is how we can start building on other people's work, so that we not only work on our own "specialized inquiries in subfields of subfields" (Glăveanu, 2014, p.12). This means that future research has to move away from the "He", the "I" and expand to the "We" focus. In addition, we claim that scientists also need to move towards the "She" (for example, our colleague), towards the "You" (others with their specializations) and also take a closer look at the "They" (e.g., cultural psychology proponents) in the research dialogue. In agreement with Glăveanu we do not want a compartmentalized creativity theory. We were in fact inspired to expand somewhat on possible creative actors and on underlying assumptions concerning values.

She. Glăveanu points to our tendency to uncritically accept implicit assumptions. When made explicit, this can tell us about the hidden dynamics underlying the surface. If the paradigmatic $\mathrm{He}$ - word gets changed into She, this perspective may focus more light on sensitive, seemingly insignificant non-verbal precursors in the creative process. These include necessary emotional and motivational roots. In the creative micro-process, these precursors eventually get more articulated at the end - stages of the creative process. The She - connotations open our minds to innumerable forgotten creators. They also open our eyes to the "He - bias" in the preference for pointing to important new technological (and military) artifacts, while not considering the possible exploitation of other cultures - in liaison with the accelerating exploitation of the Earth's natural resources. The She - connotations make us think of the fear of weakness and interdependence, which may have a share in the conception of creativity as the outcome of successful products on the market, rather than as effortful, continuous processes in our everyday lives. 
You. When the paradigmatic I is changed into You, associations highlight the emotional connections and contagion between people (a notion that is given support by the socalled mirror neurons in the brain). In people's everyday talk and interactions, explicit words are just the tip of the iceberg, while implicit messages are communicated in facial expressions, gestures and prosody. This underlines the important tension mentioned by Glăveanu (2010) between the creator and others, since phrases, statements and indeed policies explicitly stated may stand in total contrast to the factual and lived interactions between people.

They. The We-paradigm is currently the most prevalent and promising, according to Glăveanu (2010). Important tensions indicating underlying issues concerning values can be discerned here too. When switched to the word They, obviously the issue of in- or outgroups is brought into focus. Of course this may provide us with new perspectives, if we do not end up doing too much "group-think". But creative endeavors always aim to achieve a goal of some kind. At one end-pole, the creative goal for an artist can be to get relief from trauma by accomplishing symbolic expressions of the traumatic experience. At the other end-pole, the creative goal for a nation can be to secure valuable natural resources - which may instigate individual traumas. Ultimately, conflicts of interest are inherent in any artifact. As discussed by Hennessey and Altringer (2014), Hofstede categorized cultures along several dimensions, including collectivism, masculinity and long term orientation. It would be interesting to compare a culture characterized by masculinity, individualism and short term orientation, with a culture defined by femininity, collectivism and long term orientation - how would each tackle the issue of global climate change?

Other implications of opening up the stage are the challenge of developing more critical theoretical work, for example in terms of arguing and discussing definitions. Glăveanu asserts that the broadening of the definition might help researchers lift their eyes away from simple questions concerning new and useful products analyzed apart from the process. Our process definition states that creativity is "a productive or generative novel way of experiencing reality - including the perceiver's own self (Hoff \& Carlsson, 2002) and is one attempt to show that the creator and the created are difficult to separate. Glăveanu suggests that creativity is acted out within an interactional system and that we need to expand the creativity stage with actors, action, artifacts, audiences and affordances (Glăveanu, 2013). The a-words as opposed to the p-words imply that the parts of creativity cannot be broken apart into separate pieces analogous to our former professor's idea that creative perception is dependent on the experiences of the creative actor. 
In an attempt to build on already existing theory, but also to explore creative acts in new ways in order to advance theory and practical implications, our research group is developing a new measurement. Hitherto (experimental) research has mainly investigated an individual's (he) creativity while very little group creativity (she and he) has been addressed. There is a lack of instruments to assess group creativity, most probably due to problems with providing adequate controls. But our field would stagnate if we were overly concerned with controllability. As creativity is often a collaborative process (Sawyer \& DeZutter, 2009), we must be bold enough to move beyond divergent thinking tests with individuals (Glăveanu, 2014). In our creative process test, known as Distributed Creativity in Organizational Groups (DOG), groups experience a creative process, starting with idea generation phases and ending in an evaluation and selection phase (Hoff \& West, 2014). The final artifact - or creative product - is judged by a panel of judges (i. e. the Consensual Assessment Technique, CAT). The DOG not only provides a score that allows for comparison between groups (West, Hoff \& Carlsson, 2015) but it can also be related to other organizational measures as demanded by "unit-analysis psychology".

The test format also provides process material in the shape of sketches and written material, as well as observational data or experiences, for instance in the form of video recordings or follow-up interviews. The DOG builds on several ideas from other research - divergent thinking, variation-selective retention, distributed creativity and the CAT (Guilford, 1967; Campbell, 1960; Sawyer \& DeZutter, 2009; Amabile, 1982 respectively). It combines them in a new way, to be able to measure group creativity (nomothetic knowledge). But it also opens up the possibility for exploring processes, thus it represents a form of ideographic research. In a further effort to build on other people's work and inspired by Glăveanu's call for alternative definitions, we also suggest an update of our person-orientated definition from 2002. Creativity that is captured in the DOG is a collective, generative, novel way of experiencing reality ending with an idea of a shared product that is evaluated as creative in a relevant context. Both Tanggaard's (2013) concept of sociomateriality and Sawyer and De Zutter's (2009) work on distributed creativity and emergence are sources of inspiration.

Despite our colleague's worries about the lack of interest in the late professor's significant work, our new work is actually inspired by it. The micro-processes of creative action can be explored with this new tool, but in a non-experimental environment with actors working in collaboration. 


\section{REFERENCES}

Amabile, T. M. (1982). Social psychology of creativity: A consensual assessment technique. Journal of Personality and Social Psychology, 43, 5, 997-1013, DOI: 10.1037/0022-3514.43.5.997.

Brown, J. (2008). Actualization and causality. In G. Smith \& I. M. Carlsson (Eds.), Process and personality: actualization of the personal world with process-oriented methods (pp. 263-289). Frankfurt: Ontos Verlag.

Campbell, D. T. (1960). Blind variation and selective retentions in creative thought as in other knowledge processes. Psychological Review, 67, 6, 380-400; DOI: 10.1037/ h0040373.

Draguns, J. (2008). Perceptgenesis: its origins, accomplishments and prospects. In G. Smith \& I. M. Carlsson (Eds.), Process and personality: actualization of the personal world with process-oriented methods (pp. 23-51). Frankfurt: Ontos verlag.

Glăveanu, V. P. (2014). The psychology of creativity: a critical reading. Creativity. Theories - Research - Applications, 1, 1, 10-32; DOI: 10.15290/ctra.2014.01.01.02.

Glăveanu, V. P. (2010). Paradigms in the study of creativity: Introducing the perspective of cultural psychology. [Article]. New ldeas in Psychology, 28, 1, 79-93; DOI: 10.1016/ j.newideapsych.2009.07.007.

Glăveanu, V. P. (2013). Rewriting the language of creativity: The Five A's framework. Review of General Psychology, 17, 1, 69-81; DOI: 10.1037/a0029528.

Guilford, J. P. (1967). The nature of human intelligence. New York: McGraw-Hill Book Company.

Hennessey, B., \& Altringer, B. A. (2014). Kulturella skillnader: kreativitet i olika väderstreck [Cultural differences: creativity in different points of the compass]. In E. Brodin, I. M. Carlsson, E. V. Hoff \& F. Rasulzada (Eds.), Kreativitet: teori och praktik ur psykologiska perspektiv [Creativity: theory and practise from psychological perspectives] (pp. 233-255). Stockholm: Liber.

Hoff, E. V., \& West, S. (2014). Manual : Test for Distributed creativity in Organizational Groups (DOG). Lund, Sweden: Department of psychology. Lund University.

Hoff, E., \& Carlsson, I. (2002). Shining lights or lone wolves? Creativity and self-image in primary school children. Journal of Creative Behavior, 36, 1, 17-40.

Hutchins, E. (2012). Concepts in Practice as Sources of Order. Mind, Culture, and Activity, 19, 3, 314-323. 
Sawyer, R. K., \& DeZutter, S. (2009). Distributed creativity: How collective creations emerge from collaboration. Psychology of Aesthetics, Creativity, and the Arts, 3, 2, 81-92; DOI: 10.1037/a0013282.

Smith, G. (2001). The process approach to personality: perceptgeneses and kindred approaches in focus. New York: Kluwer Academic/Plenum publishers.

Smith, G., \& Carlsson, I. (1990). The creative process: a functional model based on empirical studies from early childhood to middle age (Vol. 57). Madison, Conn: International U.P.

Tanggaard, L. (2013). The sociomateriality of creativity in everyday life. [Article]. Culture \& Psychology, 19, 1, 20-32; DOI: 10.1177/1354067x12464987.

West, S., Hoff, E. V., \& Carlsson, I. M. (2015). Enhancing team creativity with playful improvisation theatre: a controlled intervention field study. Submitted for publication. Department of Psychology. Lund University. Sweden.

Corresponding author at: Eva Hoff \& Ingegerd Carlsson, Department of Psychology, Lund University, P O Box 213, SE-221 00 Lund, Sweden

E-mail: eva.hoff@psy.lu.se

E-mail: ingegerd.carlsson@psy.lu.se 